\title{
Immune response to vaccines is maintained in patients treated with dimethyl fumarate \\ OPEN
}

Christian von Hehn, MD, $\mathrm{PhD}$

Jonathan Howard, MD Shifang Liu, PhD

Ven Meka, MD

Joe Pultz, PhD

Devangi Mehta, $\mathrm{PhD}$

Claudia Prada, MD, PhD

Soma Ray, PhD

Michael R. Edwards, PhD

Sarah I. Sheikh, MD

Correspondence to

Dr. von Hehn:

Christian.vonhehn@biogen.com
Supplemental data at Neurology.org/nn

\section{ABSTRACT}

Objectives: To investigate the immune response to vaccinations in patients with relapsing forms of MS treated with delayed-release dimethyl fumarate (DMF) vs nonpegylated interferon (IFN).

Methods: In this open-label, multicenter study, patients received 3 vaccinations: (1) tetanusdiphtheria toxoid (Td) to test T-cell-dependent recall response, (2) pneumococcal vaccine polyvalent to test T-cell-independent humoral response, and (3) meningococcal (groups A, C, W-135, and $\mathrm{Y}$ ) oligosaccharide $\mathrm{CRM}_{197}$ conjugate to test T-cell-dependent neoantigen response. Eligible patients were aged 18-55 years, diagnosed with relapsing-remitting MS (RRMS), and either treated for $\geq 6$ months with an approved dose of DMF or for $\geq 3$ months with an approved dose of nonpegylated IFN. Primary end point was the proportion of patients with $\geq 2$-fold rise in antitetanus serum IgG levels from prevaccination to 4 weeks after vaccination.

Results: Seventy-one patients (DMF treated, 38; IFN treated, 33) were enrolled. The mean age was 45.3 years (range $27-55$ ); $86 \%$ were women. Responder rates ( $\geq 2$-fold rise) to $\mathrm{Td}$ vaccination were comparable between DMF- and IFN-treated groups (68\% vs $73 \%$ ). Responder rates $(\geq 2$-fold rise) were also similar between DMF- and IFN-treated groups for diphtheria antitoxoid (58\% vs 61\%), pneumococcal serotype 3 (66\% vs 79\%), pneumococcal serotype 8 (95\% vs $88 \%)$, and meningococcal serogroup C (53\% vs $53 \%)$, all $p>0.05$. In a post hoc analysis, no meaningful differences were observed between groups in the proportion of responders when stratified by age category or lymphocyte count.

Conclusions: DMF-treated patients mount an immune response to recall, neoantigens, and T-cellindependent antigens, which was comparable with that of IFN-treated patients and provided adequate seroprotection.

\section{ClinicalTrials.gov identifier: NCT02097849.}

Classification of evidence: This study provides Class II evidence that patients with RRMS treated with DMF respond to vaccinations comparably with IFN-treated patients. Neurol Neuroimmunol Neuroinflamm 2018;5:e409; doi: 10.1212/NXI.0000000000000409

\section{GLOSSARY}

AAAAI = American Academy of Allergy, Asthma \& Immunology; $\mathbf{A E}=$ adverse event; $\mathbf{C l}=$ confidence interval; $\mathbf{D M F}=$ delayed-release dimethyl fumarate; IFN = interferon; IgG = immunoglobulin G; RRMS = relapsing-remitting MS; Td = tetanus-diphtheria toxoid; $\mathbf{T}_{\mathbf{H}}=\mathrm{T}$ helper.

Delayed-release dimethyl fumarate (DMF) is an oral medication approved for the treatment of relapsing MS, a chronic autoimmune CNS disorder. ${ }^{1,2}$ Treatment with DMF reduced memory cells while expanding naive cells, ${ }^{1}$ disproportionately reduced $\mathrm{CD} 8^{+} \mathrm{T}$ cells relative to $\mathrm{CD} 4^{+}$ $\mathrm{T}$ cells, ${ }^{3-5}$ and downregulated $T$-helper $\left(\mathrm{T}_{\mathrm{H}}\right) 1$ and $\mathrm{T}_{\mathrm{H}} 17$ cytokines, leading to a $\mathrm{T}_{\mathrm{H}} 2$ bias ${ }^{6}$ indicating that DMF may shift the immune response in the CNS and the periphery.

DMF demonstrated a positive risk-benefit profile in the 2 pivotal phase 3 trials $^{7,8}$ and $>245,000$ patients have been treated with DMF, representing $>375,000$ patient-years of

From Biogen (C.v.H., S.L., V.M., J.P., D.M., C.P., S.R., M.R.E., S.I.S.), Cambridge, MA; and Multiple Sclerosis Comprehensive Care Center (J.H.), NYU Langone Medical Center, New York, NY.

Funding information and disclosures are provided at the end of the article. Go to Neurology.org/nn for full disclosure forms. The Article Processing Charge was funded by Biogen.

This is an open access article distributed under the terms of the Creative Commons Attribution-NonCommercial-NoDerivatives License 4.0 (CC BY-NC-ND), which permits downloading and sharing the work provided it is properly cited. The work cannot be changed in any way or used commercially without permission from the journal. 
exposure as of January 31, 2017. In those trials, a subsequent open-label extension study, and in the postmarketing setting, absolute lymphocyte counts were decreased by $\sim 30 \%$ and subsequently stabilized within the first 912 months after treatment initiation. ${ }^{9}$ DMF treatment has not been associated with an increased risk of infections or malignan$\operatorname{cies}^{7,8,10}$; however, very rare cases of progressive multifocal leukoencephalopathy have been reported in patients with prolonged lymphopenia (Biogen data on file and references 11 and 12).

Given the immunomodulatory properties of DMF and its observed effects on lymphocytes, further evaluation of its effects on the humoral immune response is needed. Vaccines are not only important for disease prophylaxis but also can be used to investigate immune system function by examining the response to recall antigens, neoantigens, or T-cell-independent antigens. ${ }^{13}$ Using 3 different vaccines, we assessed the ability of DMF-treated patients to respond to vaccination compared with nonpegylated interferon (IFN)-treated patients. IFN, despite its immunomodulatory effect, does not decrease the response to vaccination. ${ }^{14-16}$

METHODS Study design. The goal of this open-label multicenter study (clinicaltrials.gov NCT02097849) was to evaluate immune response to vaccination in patients with relapsing forms of MS who had been treated for $\geq 6$ months with the approved dose ( $240 \mathrm{mg}$ twice daily) of DMF or who had been treated for $\geq 3$ months with an approved dose of a nonpegylated IFN (e.g., Avonex, Betaseron, Rebif, and Extavia). Enrollment was targeted at $\sim 70$ patients ( $\sim 35$ patients per group). After a 28 -day screening period to determine eligibility, patients were assigned to groups according to MS treatment (DMF or nonpegylated IFN). Throughout the study, patients remained on their existing stable dosing regimen of DMF or nonpegylated IFN. Patients had blood sampled on day 1 for prevaccination baseline antitetanus, antipneumococcal, antimeningococcal, and antidiphtheria serum immunoglobulin $G(\operatorname{IgG})$ titers and were then vaccinated. At week 4, patients returned to the clinic for a final study visit, when a postvaccination blood sample was taken for postvaccination IgG titers. The patient's neurologist or primary health care provider managed their MS care before, during, and after study participation.

The following vaccines were used: (1) tetanus-diphtheria toxoid (Td; Tenivac; Sanofi Pasteur, Swiftwater, PA) to assess T-cell-dependent anamnestic humoral response; (2) pneumococcal vaccine polyvalent (PPSV23; Pneumovax 23; Merck \& Co., Inc., Rahway, NJ) to assess T-cell-independent humoral response; and (3) meningococcal (groups A, C, W-135, and Y) oligosaccharide $\mathrm{CRM}_{197}$ conjugate (MCV4; Menveo; Novartis
Vaccines and Diagnostics, Inc., Cambridge, MA) to assess neoantigen response.

The primary objective of the study was to evaluate the immune response to vaccination with $\mathrm{Td}$ in patients with relapsing forms of MS who have been treated with DMF vs those treated with nonpegylated IFN. The secondary objective of this study was to evaluate the immune response to vaccination with PPSV23 and MCV4. This study provides Class II evidence regarding the effect on vaccination immune response for patients with relapsing-remitting MS (RRMS) treated with DMF compared with nonpegylated IFN.

Patients. Eligible patients were aged $18-55$ years, diagnosed with relapsing forms of MS, and either treated for $\geq 6$ months with an approved dose of DMF or for $\geq 3$ months with an approved dose of nonpegylated IFN. Patients were required to have had a tetanus vaccination $2-15$ years before screening and an antitetanus serum titer at screening $\leq 50 \%$ of the upper limit of detection to ensure the potential for an adequate recall immune response. Key exclusion criteria included pneumococcal vaccination within 5 years of screening; any previous exposure to meningococcal vaccines; known hypersensitivity to Td, PPSV23, or MCV4 or their components; and clinical MS relapse requiring treatment within the 30 days before day 1 of study enrollment. Furthermore, patients were excluded if they had been treated with any type of vaccine other than the inactivated influenza vaccine within the 4 weeks before day 1 of study enrollment or had received prior treatment with immunosuppressive drugs (detailed inclusion/ exclusion criteria are provided in supplemental material at Neurology.org/nn).

Efficacy end points. The end points were chosen to investigate the seroresponse rate, as reflected in the proportion of patients with an increased postvaccination titer or an increased geometric mean titer, and also to examine the seroprotection rate. The primary end point was the proportion of patients with $\mathrm{a} \geq 2$-fold rise in antitetanus serum IgG levels from prevaccination to 4 weeks after $\mathrm{Td}$ vaccination. Secondary end points were the proportion of patients with a $\geq 4$-fold rise in antitetanus serum IgG levels from prevaccination to 4 weeks after $\mathrm{Td}$ vaccination; the proportion of patients with a $\geq 2$ - and $\geq 4$-fold rise in antipneumococcal serum $\operatorname{IgG}$ levels against serotypes 3 and 8 and antimeningococcal serogroup $\mathrm{C}$ from prevaccination to 4 weeks after PPSV23 and MCV4 vaccinations, respectively; and geometric mean titer ratios from prevaccination to 4 weeks after vaccination for antitetanus, antipneumococcal, and antimeningococcal serum IgG titers. The number of specified serotypes had to be limited in the efficacy end point; however, all serotypes were ultimately investigated. Serotype 3 was chosen as it is considered more immunogenic than others, ${ }^{13}$ and serotype 8 was chosen as it is considered to be one of the more invasive strains. ${ }^{17}$

Exploratory end points included the proportion of patients with a $\geq 2$ - and $\geq 4$-fold rise in anti-diphtheria toxoid serum IgG levels from prevaccination to 4 weeks after Td and MCV4 vaccinations; antidiphtheria geometric mean titer ratio from prevaccination to 4 weeks after MCV4 vaccination; and the proportion of patients with antitetanus, antipneumococcal, and antimeningococcal seroprotective levels at 4 weeks. Antitetanus, antipneumococcal, antimeningococcal, and antidiphtheria serum IgG titers were assessed before vaccination on day 1 and after vaccination at week 4 . Antigen-specific IgG assays were performed at Focus Diagnostics, Inc. (Cypress, CA) using clinically validated ELISAs to detect IgG antibodies. 
Safety. Safety evaluations consisted of adverse events (AEs), serious AEs, hematology and blood chemistry, urine pregnancy tests, and vital signs at day 1 and week 4 .

Statistical analysis. Antiantigen titers considered to be protective were based on the American Academy of Allergy, Asthma \& Immunology (AAAAI) guidance for diagnostic vaccines; however, it should be noted that this is an active area of research. ${ }^{13}$ Protective levels were $0.15 \mathrm{IU} / \mathrm{mL}$ for tetanus, $0.01 \mathrm{IU} / \mathrm{mL}$ for diphtheria, $1.3 \mu \mathrm{g} / \mathrm{mL}$ for pneumococcal serotypes 3 and 8 , and $2.0 \mu \mathrm{g} / \mathrm{mL}$ for meningococcal serogroup C. The ratio of the difference between IgG levels at 4 weeks after vaccination and prevaccination to IgG levels at prevaccination was used to calculate antibody response (defined as a $\geq 2$ - or $\geq 4$-fold rise). The proportion of responders to each vaccine antigen was estimated with 95\% confidence intervals (CIs) using the Clopper-Pearson exact method. Differences in the proportion of patients with an antibody response between the DMF- and IFN-treated groups were estimated with $95 \%$ CIs using the exact method. The IgG level to each antigen was summarized by geometric mean concentration for each treatment group (with $95 \% \mathrm{CI}$ ), as well as by the ratio between groups.

Analysis populations for each of the 3 vaccines (Td, PPSV23, and MCV4) comprised patients who were appropriately vaccinated per protocol, had not taken any concomitant medications

\begin{tabular}{|c|c|c|}
\hline \multicolumn{3}{|c|}{ Baseline demographics and disease characteristics at screening } \\
\hline Characteristic & $\begin{array}{l}\text { DMF } 240 \mathrm{mg} \text { BID } \\
(\mathrm{n}=38)\end{array}$ & $\begin{array}{l}\text { Nonpegylated IFN } \\
(\mathrm{n}=33)\end{array}$ \\
\hline Mean (SD) age at enrollment, $y$ & $46(6)$ & $45(8)$ \\
\hline Median (min, max) & $47(28,55)$ & $46(27,55)$ \\
\hline \multicolumn{3}{|l|}{ Age group, $n$} \\
\hline $18-29 y$ & 1 & 1 \\
\hline $30-39$ y & 6 & 7 \\
\hline $40-49$ y & 20 & 13 \\
\hline $50-55$ y & 11 & 12 \\
\hline$>55 y$ & 0 & 0 \\
\hline Female, $n(\%)$ & $34(89)$ & $27(82)$ \\
\hline \multicolumn{3}{|l|}{ Race, $n(\%)$} \\
\hline White & 35 (92) & $26(79)$ \\
\hline Black/African American & $2(5)$ & 4 (12) \\
\hline Asian & 0 & 1 (3) \\
\hline Other & 1 (3) & $2(6)$ \\
\hline Time since first MS symptoms, y, median (range) & $14.5(1-42)$ & $11.0(3-35)$ \\
\hline Time since first MS diagnosis, $y$, median (range) & $9.0(1-26)$ & $10.0(1-24)$ \\
\hline $\begin{array}{l}\text { Total no. of relapses in } 12 \text { months before } \\
\text { screening, mean (SD) }\end{array}$ & $0.3(0.7)$ & $0.2(0.5)$ \\
\hline Time on study, $d$, mean (SD) & $30(5)$ & 32 (12) \\
\hline \multicolumn{3}{|l|}{ Lymphocyte count, $n$} \\
\hline$\geq 0.91 \times 10^{3} / \mathrm{L}$ & 20 & 30 \\
\hline$<0.91 \times 10^{3} / \mathrm{L}$ & 18 & 3 \\
\hline$<0.80 \times 10^{3} / \mathrm{L}$ & 15 & 2 \\
\hline$<0.50 \times 10^{3} / \mathrm{L}$ & 2 & 1 \\
\hline
\end{tabular}

Abbreviations: $\mathrm{BID}=$ twice daily; $\mathrm{DMF}=$ delayed-release dimethyl fumarate; IFN = interferon; $\max =$ maximum; $\min =$ minimum . that could affect immune responses, and had nonmissing prevaccination and postvaccination serum IgG levels. Prevaccination serum IgG levels must have also been less than or equal to onehalf the upper limit of detection for the assay. The safety population was defined as all patients who received $\geq 1$ vaccination. Only treatment-emergent AEs were analyzed. Vaccinationemergent AEs were defined as AEs occurring or worsening after vaccination. All safety data were summarized using descriptive statistics. The incidence of AEs was summarized using frequency distribution tables by group, severity, relationship to vaccines, and overall. Changes from baseline in laboratory values and vital signs were descriptively summarized by group.

Standard protocol approvals, registrations, and patient consents. The study was conducted in accordance with the International Conference on Harmonization Good Clinical Practice guidelines and the ethical principles outlined in the Declaration of Helsinki. Investigators obtained ethics committee approval for the study protocol and amendments. The ethics committee from each participating site approved the study protocols. All patients provided written informed consent to participate in the study. This study is registered on clinicaltrials.gov (NCT02097849).

RESULTS Patients. The vaccination study ran from February 2015 to May 2016. In total, 71 patients were enrolled at 14 investigational sites in the United States; 38 patients receiving DMF treatment for $\geq 6$ months and 33 patients receiving nonpegylated IFN treatment for $\geq 3$ months were vaccinated, completed the study, and were analyzed for safety and efficacy (figure e-1). No patients withdrew from the study. Demographics and MS and MS-relapse history were generally well balanced across the 2 groups (table 1). Patients' age ranged from 27 to 55 years, with a mean age of 45.3 years. The majority of patients were women $(86 \%)$ and white $(86 \%)$. The median time since first MS diagnosis for DMF-treated patients was 9 (range 1-26) years compared with 10 (range 1-24) years for IFN-treated patients. Mean (SD) relapses in the 12 months before screening were 0.3 (0.7) for DMF-treated patients compared with $0.2(0.5)$ for IFN-treated patients. All 38 (100\%) DMF-treated patients received each of the 3 vaccines as per the study protocol. Of the 33 IFN-treated patients, all patients received the $\mathrm{Td}$ and PPSV23 vaccines; 1 patient in the IFN group did not receive the MCV4 vaccination and was not included in the MCV4 analysis.

Vaccine efficacy. Recall response. All patients enrolled in the study were previously vaccinated against tetanus, enabling assessment of T-cell-dependent anamnestic humoral response using the $\mathrm{Td}$ vaccine. A patient was considered a responder if a $\geq 2$-fold rise in $\operatorname{IgG}$ antibody levels was observed from prevaccination to 4 weeks after Td vaccination. The proportion of patients with a $\geq 2$-fold rise in titers for antitetanus was $68 \%(26 / 38)$ for the DMF-treated group and $73 \%$ (24/33) for the IFN-treated group. By comparing 
patients receiving DMF treatment and IFN treatment, no statistically significant difference was observed in the proportion of patients with $\mathrm{a} \geq 2$ - or $\geq 4$-fold rise in tetanus antitoxoid IgG levels $(-0.04$ [95\% CI -0.27 to 0.19$] ; p=0.69$ and -0.19 [95\% CI -0.41 to 0.05$] ; p=0.12$, respectively; figure 1 ). All patients enrolled had prevaccination antitetanus serum IgG levels above the level considered to be protective $(0.15 \mathrm{IU} / \mathrm{mL})^{13}$ and maintained protective levels at 4 weeks.

The change in titers for tetanus antitoxoid from individual patients from day 1 to week 4 is shown in figure 2 , indicating a comparable response pattern in DMF- and IFN-treated patients. Geometric mean titer ratios from prevaccination to 4 weeks after vaccination were similar between DMF- and IFNtreated patients for tetanus antitoxoid; 4.4 (minimum and maximum: 1.0 and 26.8) compared with 5.0 (minimum and maximum: 0.7 and 28.8), respectively (figure 3A).

Recall response was also assessed using titers for diphtheria. Antidiphtheria response was comparable between the DMF- and IFN-treated groups following the administration of the Td and MCV4 vaccines. The proportion of patients with a $\geq 2$-fold rise in titers for diphtheria antitoxoid was 58\% (22/38) for the DMF-treated group and 61\% (20/33) for the IFN-treated group, with a corresponding difference in proportions $(95 \% \mathrm{CI})$ of $-0.03(-0.26$ to 0.20$)$; $p=0.82$ (figure 1). Similarly, the difference in the proportion of patients with a $\geq 4$-fold rise in titers for diphtheria antitoxoid was not significant between the DMF-treated (42\% [16/38]) and IFN-treated (39\% [13/33]) groups $(0.03$ [95\% CI -0.20 to 0.26$] ; p=$ 0.82 ).

The change in titers for diphtheria antitoxoid from individual patients from day 1 to week 4 is shown in figure 2. Geometric mean titer ratios from prevaccination to 4 weeks after vaccination were similar between DMF- and IFN-treated patients for diphtheria antitoxoid; 3.7 (minimum and maximum: 1.0 and 21.8) compared with 3.8 (minimum and maximum: 0.5 and 40.4), respectively (figure 3A).

T-cell-independent response (pneumococcal). As a polysaccharide vaccine, PPSV23 can stimulate antibody response without $\mathrm{T}$-cell facilitation and was therefore

Figure 1 Responder rates of patients at 4 weeks compared with prevaccinated levels

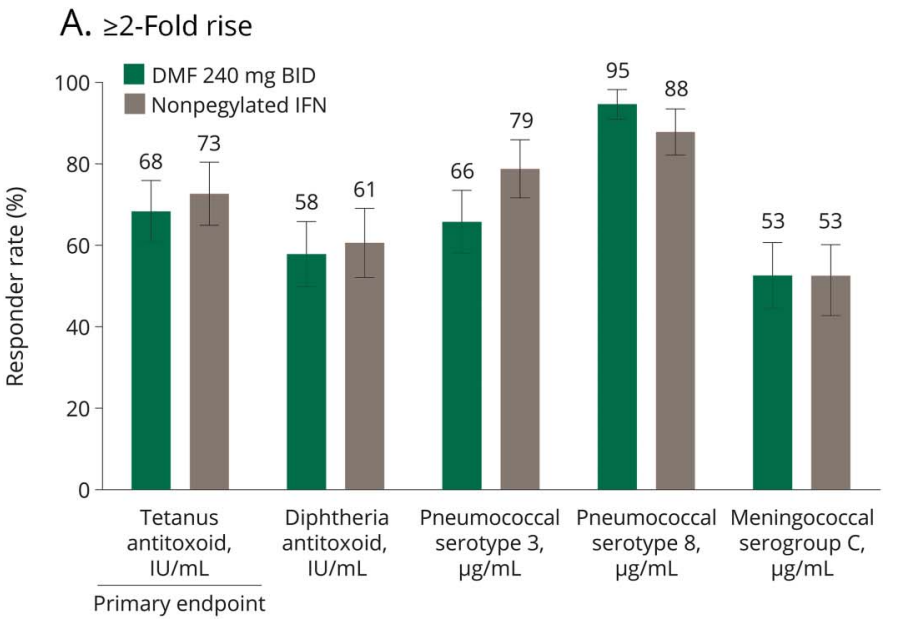

\begin{tabular}{|c|c|c|c|c|c|c|}
\hline & \multicolumn{3}{|l|}{$\geq 2$-Fold rise } & \multicolumn{3}{|l|}{$\geq 4$-Fold rise } \\
\hline & $\begin{array}{l}\text { DMF } 240 \mathrm{mg} \\
\text { BID, n (\%) }\end{array}$ & $\begin{array}{l}\text { Nonpegylated } \\
\text { IFN, n (\%) }\end{array}$ & $\begin{array}{l}\text { Difference in } \\
\text { proportion of } \\
\text { patients }(95 \% \mathrm{Cl}) \\
p \text { value }\end{array}$ & $\begin{array}{l}\text { DMF } 240 \mathrm{mg} \\
\text { BID, n (\%) }\end{array}$ & $\begin{array}{l}\text { Nonpegylated } \\
\text { IFN, n (\%) }\end{array}$ & $\begin{array}{l}\text { Difference in } \\
\text { proportion of } \\
\text { patients }(95 \% \mathrm{Cl}) \\
p \text { value }\end{array}$ \\
\hline $\begin{array}{l}\text { Tetanus } \\
\text { antitoxoid }\end{array}$ & $26 / 38(68)$ & 24/33 (73) & $\begin{array}{l}-0.04(-0.27 \text { to } 0.19) \\
0.69\end{array}$ & $16 / 38(42)$ & $20 / 33(61)$ & $\begin{array}{l}-0.19(-0.41 \text { to } 0.05) \\
0.12\end{array}$ \\
\hline $\begin{array}{l}\text { Diphtheria } \\
\text { antitoxoid }\end{array}$ & $22 / 38(58)$ & $20 / 33(61)$ & $\begin{array}{l}-0.03(-0.26 \text { to } 0.20) \\
0.82\end{array}$ & $16 / 38(42)$ & 13/33 (39) & $\begin{array}{l}0.03(-0.20 \text { to } 0.26) \\
0.82\end{array}$ \\
\hline $\begin{array}{l}\text { Pneumococcal } \\
\text { serotype } 3\end{array}$ & 25/38 (66) & 26/33 (79) & $\begin{array}{l}-0.13(-0.35 \text { to } 0.10) \\
0.23\end{array}$ & $18 / 38(47)$ & $23 / 33(70)$ & $\begin{array}{l}-0.22(-0.44 \text { to } 0.01) \\
0.06\end{array}$ \\
\hline $\begin{array}{l}\text { Pneumococcal } \\
\text { serotype } 8\end{array}$ & $36 / 38(95)$ & $29 / 33(88)$ & $\begin{array}{l}-0.07(-0.16 \text { to } 0.30) \\
0.30\end{array}$ & $31 / 38(82)$ & $28 / 33(85)$ & $\begin{array}{l}-0.03(-0.26 \text { to } 0.20) \\
0.71\end{array}$ \\
\hline $\begin{array}{l}\text { Meningococcal } \\
\text { serogroup C }\end{array}$ & $20 / 38(53)$ & $17 / 32(53)$ & $\begin{array}{l}0.00(-0.24 \text { to } 0.23) \\
0.97\end{array}$ & $14 / 38(37)$ & $12 / 32(38)$ & $\begin{array}{l}0.01(-0.24 \text { to } 0.22) \\
0.96\end{array}$ \\
\hline
\end{tabular}

B. $\geq 4$-Fold rise

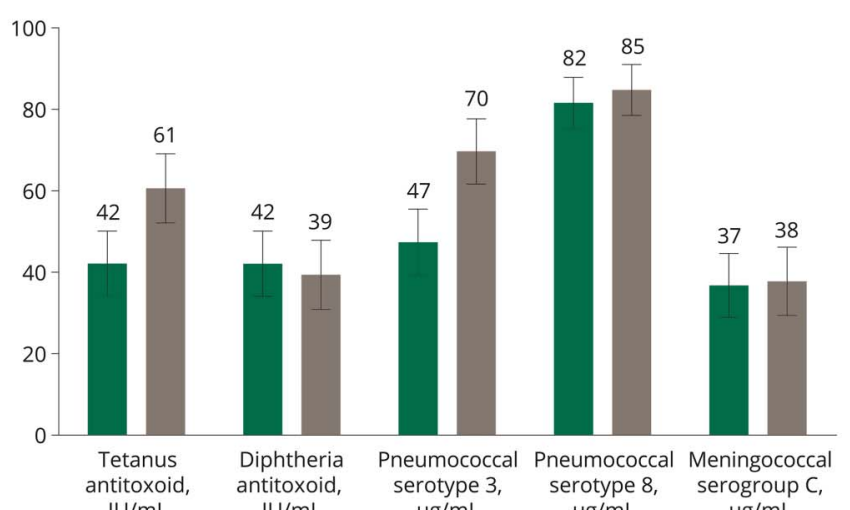

serotype 3, serotype 8

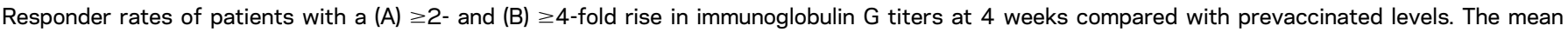

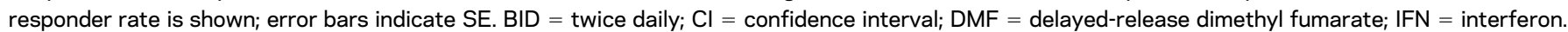


A. Tetanus antitoxoid

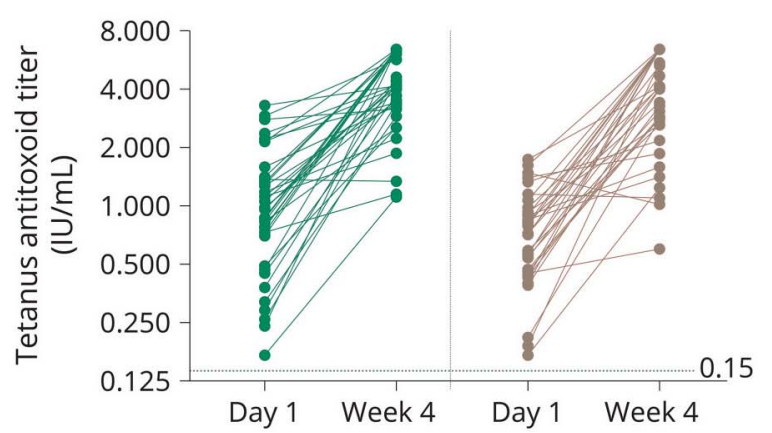

C. Pneumococcal serotype 3

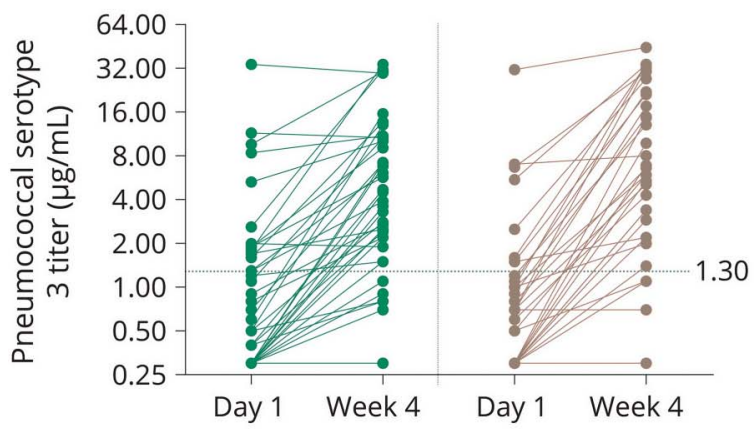

E. Meningococcal serogroup $C$

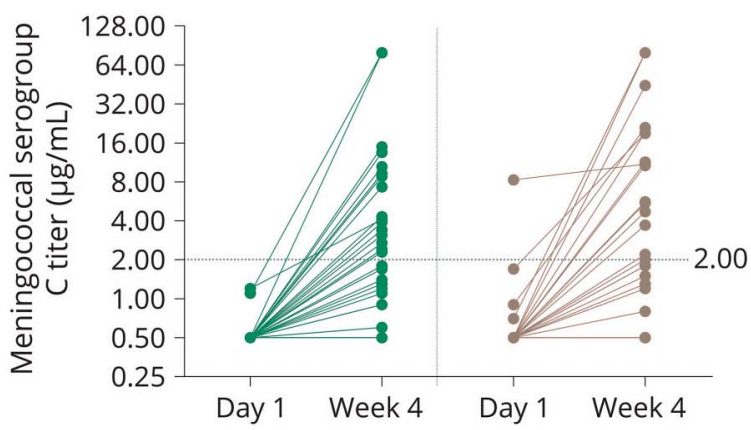

\section{B. Diphtheria antitoxoid}

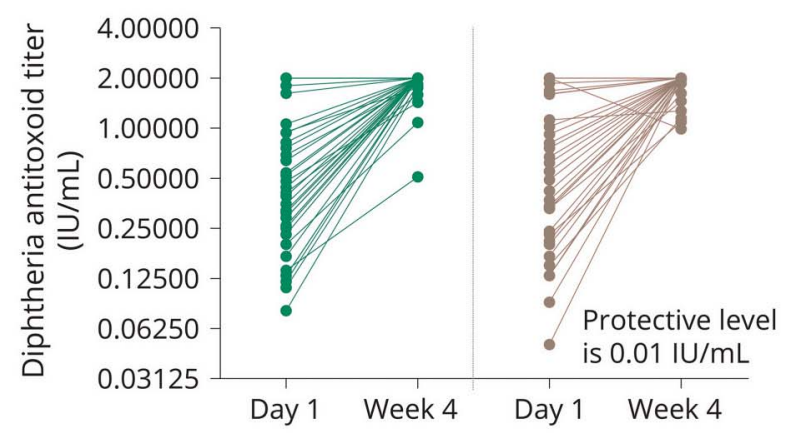

D. Pneumococcal serotype 8

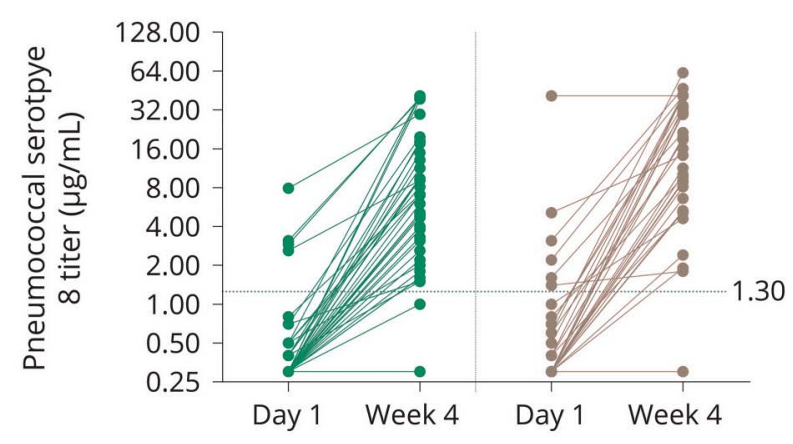

- DMF 240 mg BID

- Nonpegylated IFN

Antibody titers were assessed for (A) tetanus antitoxoid, (B) Diphtheria antitoxoid, (C) Pneumococcal serotype 3, (D) Pneumococcal serotype 8, and (E) Meningococcal serotype C. BID = twice daily; DMF = delayed-release dimethyl fumarate; IFN = interferon.

used to evaluate T-cell-independent humoral response. As per the protocol, the focus was on $2 / 23$ serotypes of the PPSV23 vaccine; however, the response to all 23 serotypes was analyzed. The difference in the proportion of patients with a $\geq 2$ - or $\geq 4$ fold rise in antipneumococcal serum IgG levels against serotype 3 or 8 was not significantly different between the DMF- and IFN-treated groups (figure 1). Similarly, the difference in the proportion of patients with $\mathrm{a} \geq 2$ - or $\geq 4$-fold increase in antipneumococcal serum IgG levels against the remaining 21 serotypes was not statistically different between the 2 groups. The change in titers for pneumococcal antitoxoid from individual patients from day 1 to week 4 is shown in figure 2 .

Geometric mean titer ratios from prevaccination to 4 weeks after vaccination were similar between DMF- and IFN-treated patients for PPSV23 vaccine serotype 3 (4.7 [minimum and maximum: 0.9 and 26.2] vs 7.9 [minimum and maximum: 1.0 and 48.7], respectively) and for serotype 8 (14.0 [minimum and maximum: 1.0 and 137.3] vs 21.3 [minimum and maximum: 1.0 and 136.7], respectively), as well as for the other serotypes of PPSV23 (figure 3A).

The proportion of patients with antipneumococcal seroprotective levels $(\geq 1.3 \mu \mathrm{g} / \mathrm{mL})$ against serotypes 3 and 8 after PPSV23 vaccination was very similar between the 2 groups: $84 \%(32 / 38)$ in the DMF-treated group compared with 88\% (29/33) in the IFN-treated group for serotype 3, and 95\% (36/ 38 ) in the DMF-treated group compared with $97 \%$ $(32 / 33)$ in the IFN-treated group for serotype 8 . The proportion of patients with antipneumococcal 
A. Geometric mean titer ratio

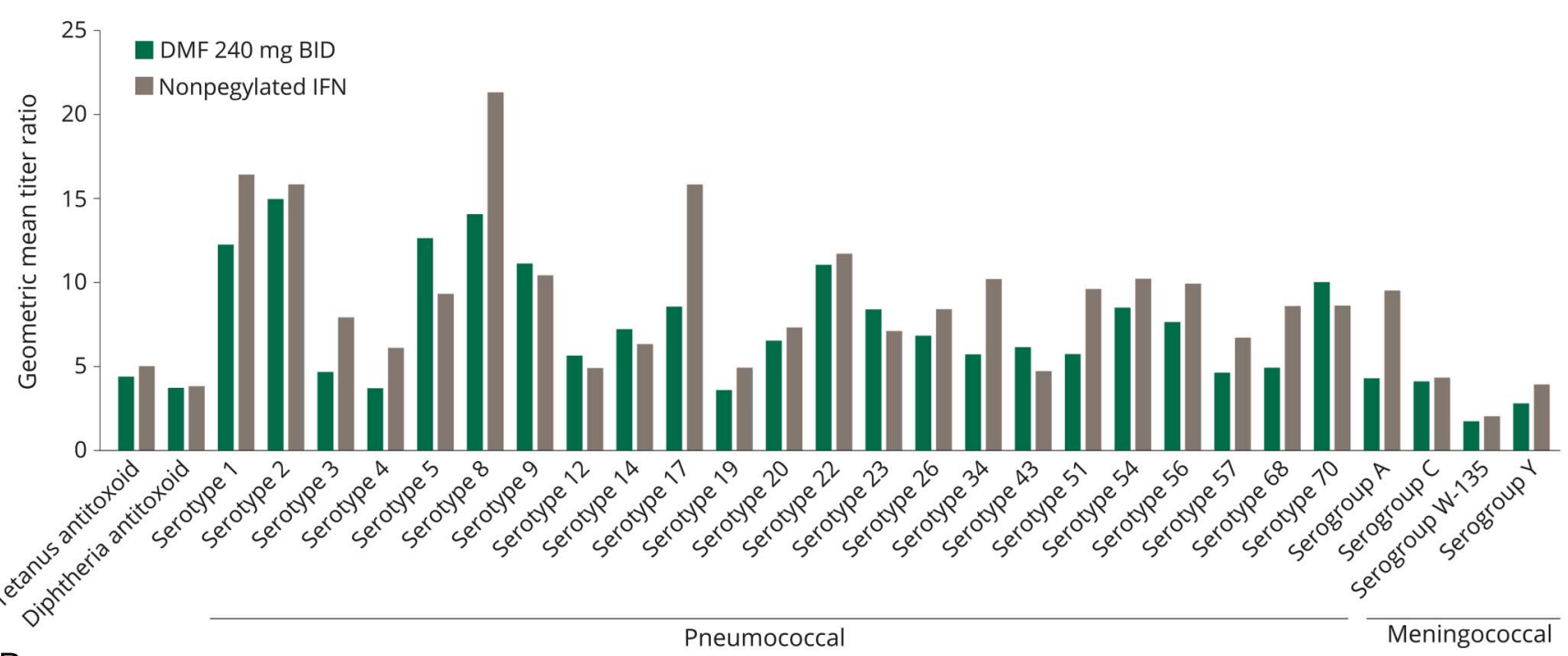

B. Seroprotection

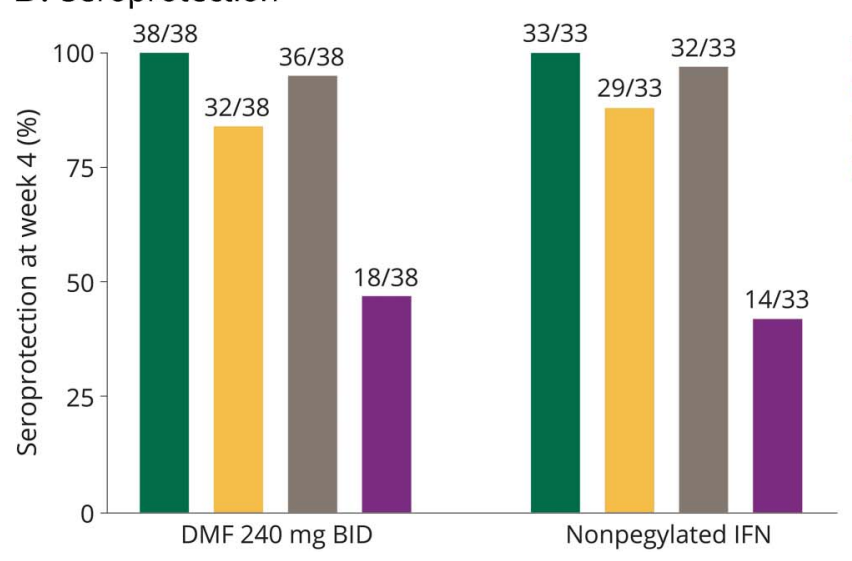

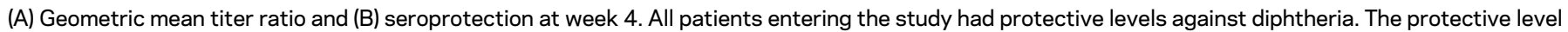

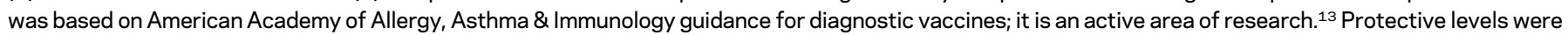

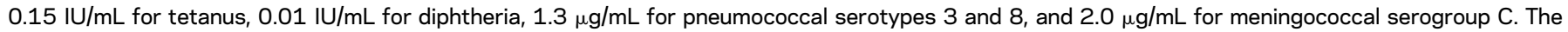

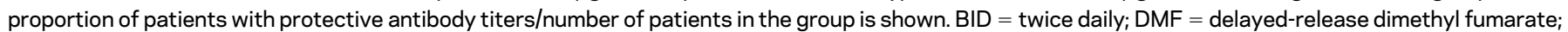
IFN = interferon.

seroprotective levels was also similar for the other serotypes of PPSV23 (figure 3).

Neoantigen response (meningococcal). MCV4 was used as a neoantigen to assess T-cell-dependent humoral response to a novel antigen. Four weeks after vaccination, no statistically significant difference was observed between the DMF- and IFN-treated groups in the proportion of patients with $\mathrm{a} \geq 2$ - or $\geq 4$-fold rise in antimeningococcal serum IgG levels against serogroup $\mathrm{C}$ or against the other serogroups (figure 1). The proportion of patients with $\mathrm{a} \geq 2$-fold rise in antimeningococcal serum IgG levels against serogroup C was 53\% (20/38) for the DMF-treated group and $53 \%(17 / 32)$ for the IFNtreated group (0.00 [95\% CI -0.24 to 0.23$] ; p=0.97$ ).

The change in titers for antimeningococcal toxoid from individual patients from day 1 to week 4 is shown in figure 2 .
Geometric mean titer ratios from prevaccination to 4 weeks after vaccination were similar between DMF- and IFN-treated patients for MCV4 vaccine serogroup $\mathrm{C}$, as well as for the other 3 serogroups contained in this vaccine (4.1 [minimum and maximum: 1.0 and 159.0 ] vs 4.3 [minimum and maximum: 1.0 and 159.0], respectively; figure 3A). The proportion of patients with antimeningococcal $\mathrm{IgG}$ levels $>2.0 \mu \mathrm{g} / \mathrm{mL}$ (considered to be protective) was comparable between the 2 groups for all MCV4 serogroups (figure $3 \mathrm{~B}$ ).

Vaccine response by age category and absolute lymphocyte counts. Mean absolute lymphocyte counts decrease by $\sim 30 \%$ during the first year of DMF treatment, then stabilize over time, ${ }^{9}$ and in some patients they remain below the lower limit of normal. To investigate the effect of low lymphocyte counts with respect to the 
Table 2 Overall summary of AEs

\begin{tabular}{|c|c|c|}
\hline$A E, n(\%)$ & DMF 240 mg BID $(n=38)$ & Nonpeg \\
\hline Vaccination-emergent $\mathrm{AE}$ & $16(42)$ & $18(55)$ \\
\hline Mild & $9(24)$ & 9 (27) \\
\hline Moderate & $7(18)$ & 7 (21) \\
\hline Severe $^{a}$ & 0 & $2(6)$ \\
\hline Serious AE & 0 & 0 \\
\hline \multicolumn{3}{|l|}{ Vaccination-emergent $A E$ by SOC } \\
\hline General disorders and administration site conditions & $11(29)$ & $11(33)$ \\
\hline Infections and infestations & 1 (3) & $4(12)$ \\
\hline Musculoskeletal and connective tissue disorders & $3(8)$ & $4(12)$ \\
\hline Nervous system disorders & $2(5)$ & $4(12)$ \\
\hline Skin and subcutaneous tissue disorders & 0 & 3 (9) \\
\hline Blood and lymphatic system disorders & 0 & 1 (3) \\
\hline Ear and labyrinth disorders & 0 & 1 (3) \\
\hline Injury, poisoning, and procedural complications & 0 & 1 (3) \\
\hline Investigations & 1 (3) & 1 (3) \\
\hline Renal and urinary disorders & 1 (3) & 1 (3) \\
\hline Respiratory, thoracic, and mediastinal disorders & 1 (3) & 1 (3) \\
\hline Vascular disorders & 0 & 1 (3) \\
\hline Neoplasms benign, malignant, and unspecified & 1 (3) & 0 \\
\hline
\end{tabular}

Abbreviations: $\mathrm{AE}=$ adverse event; $\mathrm{BID}=$ twice daily; $\mathrm{DMF}=$ delayed-release dimethyl fumarate; IFN = interferon; $\mathrm{SOC}=$ System Organ Class.

${ }^{\text {a }}$ Two patients reported severe AEs that included injection site cellulitis, burning sensation, and arthralgia.

humoral immune response, a post hoc analysis was conducted that stratified patients by the lymphocyte count. Furthermore, to examine whether age, or immunosenescence, could be an influencing factor, patients were also categorized by age. However, it should be noted that this trial was not designed or powered to study these subgroups. No meaningful differences were observed in the proportion of responders between the 2 groups when patients were stratified by the age category $(18-35,36-40,41-$ 50 , and $>50$ years). When stratified by the lowest lymphocyte count recorded during the study, the proportion of responders with lymphocyte counts less than the lower limit of normal $\left(<0.91 \times 10^{9} / \mathrm{L}\right)$ was similar to those with normal lymphocyte counts $\left(\geq 0.91 \times 10^{9} / \mathrm{L}\right)$ in both groups for all 3 vaccines. No meaningful differences were observed between DMF- and IFN-treated groups (data not shown).

Safety. All 3 vaccinations were well tolerated by patients in both the DMF- and IFN-treated groups (table 2). The incidence of vaccination-emergent AEs was similar in both groups (DMF, 42\% [16/38] and IFN, 55\% [18/33]). The most common AEs in both groups were localized to the injection site. AEs were mostly mild or moderate in severity. Two (6\%) patients reported severe AEs in the IFN-treated group: injection site cellulitis, burning sensation, and arthralgia. One patient experienced an intraductal carcinoma in situ of the breast that was considered not related to the study treatment. No vaccination-emergent $\mathrm{AEs}$ or serious $\mathrm{AEs}$ leading to study withdrawal were reported; no deaths were reported. No meaningful differences in clinical laboratory parameters or vital signs were observed between the 2 groups.

DISCUSSION Given the immunomodulatory properties of DMF and its effect on lymphocyte counts, further evaluation of the effect of DMF on immune function was needed. This study assessed the ability of DMF-treated vs nonpegylated IFN-treated patients with relapsing forms of MS to respond to vaccination with recall antigen (Td), T-cell-independent antigen (PPSV23), and a neoantigen (MCV4). IFN-treated patients were selected as a control because it has been shown that treatment with IFN $\beta$-1a does not decrease response to vaccination. ${ }^{14,15}$ The $\mathrm{Td}$ vaccine was selected based on its ability to elicit a T-cell-dependent anamnestic humoral response; T-cell-independent humoral response was investigated using the PPSV23 vaccine. Finally, MCV4 was used to gauge a T-celldependent humoral response to a neoantigen. 
DMF may act through the nuclear factor (erythroid-derived 2)-related factor 2-dependent and independent pathways. ${ }^{18,19}$ Studies of patients with MS indicate that DMF treatment causes a disproportionate reduction in $\mathrm{CD}^{+} \mathrm{T}$ lymphocytes compared with $\mathrm{CD}^{+} \mathrm{T}$ lymphocytes ${ }^{1,4}$ and a reduction in the number of circulating memory $\mathrm{T}$ cells and a concomitant expansion of naive $T$ cells, irrespective of the absolute lymphocyte count,${ }^{1}$ indicating that DMF works through multiple mechanisms to reduce inflammatory response in both the peripheral immune system and CNS.

The immune response to vaccination in patients with RRMS treated for $\geq 6$ months with DMF was found to be comparable with that of IFN-treated patients. DMF-treated patients can mount an adequate immune response to inactivated vaccinations according to the AAAAI guidelines. ${ }^{13}$ The primary analysis demonstrated no statistically significant difference in the proportion of $\mathrm{Td}$ vaccination responders (defined as a $\geq 2$-fold rise) between the 2 groups (68\% in DMF-treated patients vs $73 \%$ in IFNtreated patients, difference in the proportions $[95 \%$ $\mathrm{CI}]$ of $-0.4[-0.27$ to 0.19$] p=0.69)$. Secondary analyses further confirmed no significant difference in the proportion of responders (defined as patients with $\mathrm{a} \geq 2$ - and $\geq 4$-fold rise in IgG levels from prevaccination to 4 weeks postvaccination) between DMFand IFN-treated patients after PPSV23 and MCV4 vaccines.

In addition to an increase in antibody titer levels, the proportion of patients who mounted seroprotection from vaccination was also assessed. Seroprotection can be defined by either a certain titer threshold or additional assays. In this study, seroprotection was defined only by a titer threshold. All patients entering the study had antitetanus seroprotective levels. The proportion of patients who developed antipneumococcal and antimeningococcal seroprotection was directly comparable between the 2 groups. It should be noted that only IgG levels were measured because of technical limitations. Furthermore, IgM titers may have been significantly higher, especially for neoantigens such as MCV4. For example, all 4 MCV4 serogroups were analyzed in a post hoc analysis, which showed that the serogroup W-135 had the lowest geometric mean ratio for both IFN- and DMF-treated patients. Because W-135 is more often associated with Neisseria meningitidis infections outside rather than within the United States and Europe, ${ }^{20}$ the IgG response would be expected to be lower than the IgM response. Protective thresholds, especially for MCV4 and PPSV23, are an active area of research; for this study, protective antibody levels were based on the AAAAI guidance for diagnostic vaccines. ${ }^{13}$ Geometric mean
IgG titers increased 4 weeks after vaccination, and the geometric mean titer ratios were generally similar between the 2 groups, with slightly higher ratios for PPSV23 in the IFN-treated group compared with the DMF-treated group. Given the lack of significant difference in the proportion of responders between the 2 groups and the fact that the proportion of patients with antipneumococcal seroprotective levels was similar after PPSV23 vaccination, the higher geometric mean ratios observed for PPSV23 in IFN-treated patients are likely a general variation in the response between 2 fairly small populations. An additional contributing factor could be that type 1 IFNs are considered immune stimulants, and have been shown in preclinical models to enhance response to vaccinations. ${ }^{21,22}$ In a post hoc analysis, the proportion of responders with lymphocyte counts $<0.91 \times 10 \%$ was similar to those with normal lymphocyte counts, i.e., lower limit of normal of $\geq 0.91 \times 10^{9} / \mathrm{L}$ for all 3 vaccines, and no meaningful differences were observed between the 2 groups. However, it should be noted that the number of patients with low lymphocyte counts was small and that this study was not designed to investigate this subgroup; therefore, interpretation of vaccination efficacy in patients with pronounced lymphopenia should be made with caution.

Patients with MS mount an immune response similar to healthy individuals, ${ }^{23}$ but some differences may exist. An important strength of this study is that it was conducted in patients with MS, not healthy volunteers, and therefore may be more comparable with the realworld experience of patients treated with DMF.

From an immune diagnostic perspective, there was no evidence of a class effect where vaccine response to an antigen group was specifically reduced during DMF treatment. In addition, the overall responder rate indicates that DMF treatment does not inhibit humoral immune function. These findings are in line with long-term safety experiences of DMF in patients with MS, showing no overall increased risk of infections or malignancies. In conclusion, DMF-treated patients mount an adequate immune response to inactivated vaccines.

\section{AUTHOR CONTRIBUTIONS}

Christian von Hehn, Jonathan E. Howard, Shifang Liu, Devangi Mehta, Claudia Prada, Soma Ray, Michael R. Edwards, and Sarah I. Sheikh contributed to the development of the study design and data interpretation. Shifang Liu, Ven Meka, and Joe Pultz were involved in the data analysis and interpretation. All authors were involved in the development, review, and revision of the manuscript.

\section{ACKNOWLEDGMENT}

The authors are grateful to all investigators and patients participating in the study. Karen Spach from Excel Scientific Solutions wrote the first draft of the manuscript based on the input from the authors, and Elizabeth Cassell from Excel Scientific Solutions copyedited and styled the manuscript as per 
the journal's requirements. Biogen reviewed and provided feedback on the article to the authors. The authors had full editorial control of the article and provided their final approval of all content.

\section{STUDY FUNDING}

This study was supported by Biogen (Cambridge, MA). Biogen provided funding for medical writing support in the development of this manuscript.

\section{DISCLOSURE}

C. von Hehn is employed by and holds stock in Biogen. J.E. Howard received travel funding and/or speaker honoraria from Genzyme and Mallinckrodt; receives royalties from Demos-Springer; and served as an expert witness for Sbrogna and Brunelle. S. Liu is employed by and receives stock from Biogen. V. Meka was employed by Biogen; is currently employed by AstraZeneca; and received stock from Biogen. J. Pultz reports no disclosures. D. Mehta is employed by and holds stock in Biogen. C. Prada is employed by, gave expert testimony for, and holds stock in Biogen. S. Ray was employed by Biogen and is currently employed by Vertex. M.R. Edwards is a medical director at and holds stock in Biogen. S.I. Sheikh is employed by and holds stock in Biogen. Go to Neurology. org/nn for full disclosure forms.

Received April 21, 2017. Accepted in final form September 13, 2017.

\section{REFERENCES}

1. European Medicines Agency. Tecfidera gastro-resistant hard capsules [summary of product characteristics]. Available at: ema.europa.eu/docs/en_GB/document_library/ EPAR_-_Product_Information/human/002601/WC50016 2069.pdf. Accessed August 11, 2016.

2. Biogen, Inc. Tecfidera [prescribing information]. Cambridge, MA: Biogen; 2017.

3. Longbrake EE, Ramsbottom MJ, Cantoni C, Ghezzi L, Cross AH, Piccio L. Dimethyl fumarate selectively reduces memory $\mathrm{T}$ cells in multiple sclerosis patients. Mult Scler 2016;22:1061-1070.

4. Spencer CM, Crabtree-Hartman EC, Lehmann-Horn K, Cree BA, Zamvil SS. Reduction of CD8(+) T lymphocytes in multiple sclerosis patients treated with dimethyl fumarate. Neurol Neuroimmunol Neuroinflamm 2015;2: e76. doi: 10.1212/NXI.0000000000000076.

5. Fleischer V, Friedrich M, Rezk A, et al. Treatment response to dimethyl fumarate is characterized by disproportionate CD8+ $\mathrm{T}$ cell reduction in MS. Mult Scler 2017:1352458517703799.

6. Ghoreschi K, Bruck J, Kellerer C, et al. Fumarates improve psoriasis and multiple sclerosis by inducing type II dendritic cells. J Exp Med 2011;208:2291-2303.

7. Gold R, Kappos L, Arnold DL, et al. Placebo-controlled phase 3 study of oral BG-12 for relapsing multiple sclerosis. N Engl J Med 2012;367:1098-1107.

8. Fox RJ, Miller DH, Phillips JT, et al; CONFIRM Study Investigators. Placebo-controlled phase 3 study of oral BG12 or glatiramer in multiple sclerosis. N Engl J Med 2012; 367:1087-1097.

9. Fox RJ, Chan A, Gold R, et al. Characterizing absolute lymphocyte count profiles in dimethyl fumarate-treated patients with MS: patient management considerations. Neurol Clin Pract 2016;6:220-229.

10. Gold R, Arnold DL, Bar-Or A, et al. Long-term effects of delayed-release dimethyl fumarate in multiple sclerosis: interim analysis of ENDORSE, a randomized extension study. Mult Scler 2017;23:253-265.

11. Rosenkranz T, Novas M, Terborg C. PML in a patient with lymphocytopenia treated with dimethyl fumarate. $\mathrm{N}$ Engl J Med 2015;372:1476-1478.

12. Baharnoori M, Lyons J, Dastagir A, Koralnik I, Stankiewicz JM. Nonfatal PML in a patient with multiple sclerosis treated with dimethyl fumarate. Neurol Neuroimmunol Neuroinflamm 2016;3:e274. doi: 10.1212/NXI.0000000000000274.

13. Orange JS, Ballow M, Stiehm ER, et al. Use and interpretation of diagnostic vaccination in primary immunodeficiency: a working group report of the Basic and Clinical Immunology Interest Section of the American Academy of Allergy, Asthma \& Immunology. J Allergy Clin Immunol 2012;130(suppl 3):S1-S24.

14. Olberg HK, Cox RJ, Nostbakken JK, Aarseth JH, Vedeler $\mathrm{CA}$, Myhr KM. Immunotherapies influence the influenza vaccination response in multiple sclerosis patients: an explorative study. Mult Scler 2014;20:1074-1080.

15. Schwid SR, Thorpe J, Sharief M, et al. Enhanced benefit of increasing interferon beta-1a dose and frequency in relapsing multiple sclerosis: the EVIDENCE Study. Arch Neurol 2005;62:785-792.

16. Schwid SR, Decker MD, Lopez-Bresnahan M. Immune response to influenza vaccine is maintained in patients with multiple sclerosis receiving interferon beta-1a. Neurology 2005;65:1964-1966.

17. Song JY, Nahm MH, Moseley MA. Clinical implications of pneumococcal serotypes: invasive disease potential, clinical presentations, and antibiotic resistance. J Korean Med Sci 2013;28:4-15.

18. Fox RJ, Kita M, Cohan SL, et al. BG-12 (dimethyl fumarate): a review of mechanism of action, efficacy, and safety. Curr Med Res Opin 2014;30:251-262.

19. Nguyen T, Sherratt PJ, Pickett CB. Regulatory mechanisms controlling gene expression mediated by the antioxidant response element. Annu Rev Pharmacol Toxicol 2003;43:233-260.

20. Hedari CP, Khinkarly RW, Dbaibo GS. Meningococcal serogroups A, C, W-135, and Y tetanus toxoid conjugate vaccine: a new conjugate vaccine against invasive meningococcal disease. Infect Drug Resist 2014;7:85-99.

21. Proietti E, Bracci L, Puzelli S, et al. Type I IFN as a natural adjuvant for a protective immune response: lessons from the influenza vaccine model. J Immunol 2002;169:375-383.

22. Yoo JK, Baker DP, Fish EN. Interferon-beta modulates type 1 immunity during influenza virus infection. Antiviral Res 2010;88:64-71.

23. Williamson EM, Chahin S, Berger JR. Vaccines in multiple sclerosis. Curr Neurol Neurosci Rep 2016;16:36. 


\section{Neurology \\ Neuroimmunology \& Neuroinflammation}

Immune response to vaccines is maintained in patients treated with dimethyl fumarate Christian von Hehn, Jonathan Howard, Shifang Liu, et al.

Neurol Neuroimmunol Neuroinflamm 2018;5;

DOI 10.1212/NXI.0000000000000409

This information is current as of November 15, 2017

Neurol Neuroimmunol Neuroinflamm is an official journal of the American Academy of Neurology.

Published since April 2014, it is an open-access, online-only, continuous publication journal. Copyright

Copyright $\odot 2017$ The Author(s). Published by Wolters Kluwer Health, Inc. on behalf of the American

Academy of Neurology.. All rights reserved. Online ISSN: 2332-7812.

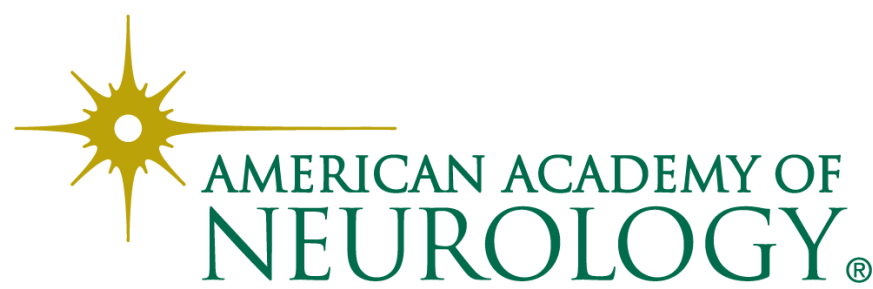




\section{Updated Information \& Services}

\section{Supplementary Material}

\section{References}

Citations

Subspecialty Collections

Permissions \& Licensing

Reprints including high resolution figures, can be found at: http://nn.neurology.org/content/5/1/e409.full.html

Supplementary material can be found at: http://nn.neurology.org/content/suppl/2018/01/04/5.1.e409.DC1

This article cites 20 articles, 3 of which you can access for free at: http://nn.neurology.org/content/5/1/e409.full.html\#\#ref-list-1

This article has been cited by 1 HighWire-hosted articles: http://nn.neurology.org/content/5/1/e409.full.html\#\#otherarticles

This article, along with others on similar topics, appears in the following collection(s):

\section{All Immunology}

http://nn.neurology.org//cgi/collection/all_immunology

\section{All Infections}

http://nn.neurology.org//cgi/collection/all_infections

Multiple sclerosis

http://nn.neurology.org//cgi/collection/multiple_sclerosis

Information about reproducing this article in parts (figures,tables) or in its entirety can be found online at:

http://nn.neurology.org/misc/about.xhtml\#permissions

Information about ordering reprints can be found online: http://nn.neurology.org/misc/addir.xhtml\#reprintsus

Neurol Neuroimmunol Neuroinflamm is an official journal of the American Academy of Neurology.

Published since April 2014, it is an open-access, online-only, continuous publication journal. Copyright

Copyright $\odot 2017$ The Author(s). Published by Wolters Kluwer Health, Inc. on behalf of the American Academy of Neurology.. All rights reserved. Online ISSN: 2332-7812.

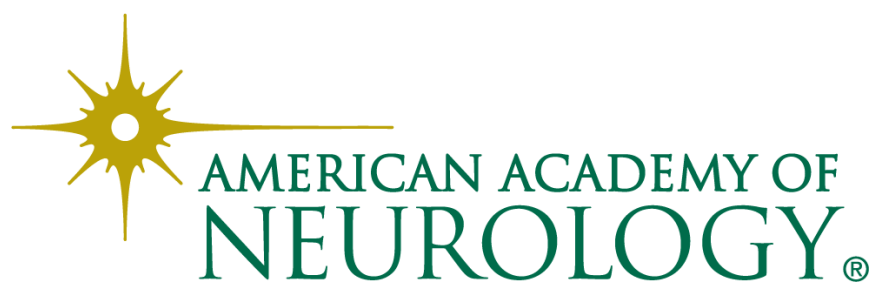

